\title{
APLICAÇÃO DA TÉCNICA DE ELETRODIÁLISE NO TRATAMENTO DE EFLUENTES DE TINGIMENTO DE GEMAS CONTENDO ÍONS NITRATO E CROMO
}

\author{
Maria de Lourdes Martins Magalhães, Verônica Radaelli Machado, Eduardo Miranda Ethur e Simone Stülp* \\ Centro de Ciências Exatas e Tecnológicas, Univates, 95900-000 Lajeado - RS, Brasil.
}

Recebido em 26/04/2016; aceito em 02/06/2016; publicado na web em 01/08/2016

\begin{abstract}
APPLICATION OF ELECTRODIALYSIS TO THE TREATMENT OF EFFLUENT FROM THE AGATE DYEING INDUSTRY WITH NITRATE AND CHROMIUM IONS. The dyeing agate employs large quantities of potentially harmful wastewater to the environment, such as, effluent with chromium and nitrate ions. The aim of the present study was investigate the electrodialysis technique efficiency in the removal of contaminant ions present in wastewater generated by the agate dyeing industry and evaluate the toxicity of the effluent studied. The electrodialysis experiments were performed in acrylic cell 5 compartments separated by ion selective membranes and fitted with a $70 \mathrm{TiO}_{2} / 30 \mathrm{RuO}_{2}$ DSA® anode and a titanium plate as cathode. After application of the electrodialysis treatment, toxicity of the effluent was evaluated in two different trophic levels, Artemia salina and Lactuca sativa. The results indicated the removal of $233.3 \mathrm{mg} \mathrm{L}^{-1}$ of nitrate and $223.6 \mathrm{mg} \mathrm{L}^{-1}$ of chromium was extracted, in flow mode. The toxicity tests showed a tendency to decrease the percentage of mortality of organisms after application of the electrodialysis technique. Thus, it concludes that the electrodialysis is an effective method for treating effluents containing metal ions, and is possible reuse the recovered solutions in the dyeing process.
\end{abstract}

Keywords: electrodialysis; wastewater treatment; toxicity; clean technologies.

\section{INTRODUÇÃO}

O Brasil destaca-se mundialmente pela diversidade de gemas encontradas em seu solo. O estado do Rio Grande do Sul apresenta um dos maiores centros de produção gemológica do país. ${ }^{1}$ Alguns municípios concentram um alto número de indústrias de processamento com empresas de pequeno, médio e grande porte que atuam no setor de beneficiamento de gemas. Dentre estas, destaca-se a ágata, que pode ser utilizada em sua forma natural ou modificada, na maioria das vezes, por processos de tingimento com corantes e obtenção de várias colorações como rosa, roxa, verde e vermelha. ${ }^{2}$

Os processos convencionais de tingimento envolvem tratamentos térmicos ${ }^{3}$ e empregam corantes orgânicos sintéticos tais como cristal violeta e rodamina-B, ${ }^{4}$ além de soluções contendo nitrato, cianeto ou amônio e complexos de cromo ou ferro ${ }^{2}$ e têm gerado consideráveis volumes de efluentes líquidos caracterizados por colorações acentuadas, concentrações elevadas de íons de vários metais, além de alta carga orgânica, tendo como consequências a geração de um passivo ambiental, já que esses corantes são potenciais contaminantes.

Atualmente, há um crescente interesse em processos alternativos de tratamento de águas residuais que gerem o mínimo de agressão ao meio ambiente, sejam economicamente viáveis e permitam o reuso da água. Estudos na área de tratamento de efluentes dos tingimentos de gemas têm sido realizados a partir de processos fotocatalíticos e de adsorção no caso da remoção da rodamina-B, ${ }^{5}$ métodos fotocatalíti$\cos ^{6}$ e de biossorção ${ }^{7}$ para a degradação do cristal violeta, além dos métodos de oxidação química ${ }^{8}$ e por Fenton, ${ }^{9}$ que visam a remoção dos componentes orgânicos. Entretanto, há a necessidade de técnicas que permitam a remoção dos íons metálicos presentes nesses efluentes.

A eletrodiálise (ED) é uma técnica eletroquímica que tem sido empregada na dessalinização da água ${ }^{10}$ e no tratamento de águas residuais para a remoção de íons como, por exemplo, cádmio, ${ }^{11}$ cromo, ${ }^{12,13}$ e nitrato, ${ }^{14-17}$ na qual espécies iônicas em solução são transportadas em compartimentos de uma célula através de membranas

*e-mail: stulp@univates.br íon-seletivas, aniônica e catiônica, por ação de um campo elétrico, ${ }^{18}$ sem a necessidade da adição de reagentes químicos. A ED apresenta benefícios quando comparada aos processos tradicionais, ${ }^{19,20}$ já que não demanda mudança de fases, funciona de forma contínua, não requer adição de reagentes, além de minimizar a geração de resíduos poluentes ao meio ambiente. Com base em algumas aplicações, como o tratamento de efluentes, a ED surge como uma tecnologia limpa e demonstra a possibilidade de reuso dos íons presentes inicialmente no efluente e da água.

Neste sentido, o objetivo do presente trabalho é avaliar a eficiência da técnica de ED na extração de íons presentes em efluentes gerados pelo tingimento de ágatas em célula de 5 compartimentos. Além disso, propõe-se investigar a toxicidade do efluente estudado, antes e após a aplicação da técnica de ED, vislumbrando possibilidades de reuso.

\section{PARTE EXPERIMENTAL}

\section{Aplicação do tratamento de eletrodiálise}

Os experimentos de ED foram realizados em célula de acrílico de 5 compartimentos, ${ }^{21}$ sendo que no compartimento central foi adicionado o efluente a ser tratado. O efluente estudado é um efluente real proveniente de indústria de beneficiamento de gemas localizada no RS, constituído de soluções de lavagem provenientes do pós-tingimento verde e vermelho ${ }^{2}$ de ágatas, que contém em meio ácido íons tais como ferro, cromo $\left(\mathrm{Cr}^{6+} \mathrm{e} \mathrm{Cr}^{3+}\right)$, nitrato e amônio. A corrente elétrica aplicada no sistema de ED foi de 2,2 A, com base em estudos prévios de corrente limite por meio de curvas de polarização (Figura $1 \mathrm{~S}$ - Material suplementar), e o potencial de célula era de $30 \mathrm{~V}$.

A célula de eletrodiálise em escala laboratorial foi construída em material acrílico transparente e compõe 5 compartimentos separados por membranas íon seletivas (Figura 1) e seu volume total aproximado é de 7 litros, sendo 1,4 L por compartimento. Como ânodo foi utilizado um eletrodo de $70 \mathrm{TiO}_{2} / 30 \mathrm{RuO}_{2} \mathrm{DSA}{ }^{\circledR}$ e como cátodo uma placa de titânio De Nora com áreas de imersão de 189 $\mathrm{cm}^{2}$. As membranas ânion e cátion seletivas são Selemion AMV e 
Selemion CMV, respectivamente, com uma área de $63,61 \mathrm{~cm}^{2}$. Os compartimentos laterais foram preenchidos com uma solução de sulfato de sódio $0,2 \mathrm{~mol} \mathrm{~L}^{-1}$ como solução eletrolítica, ${ }^{22,23}$ concentração esta que foi utilizada por questões de design e resistência elétrica da célula eletrodialítica. ${ }^{24}$ Para a aplicação de corrente no sistema foi utilizada uma fonte de corrente constante ICEL PS 7000 (0-35 V; 0-3 A). O tempo de tratamento aplicado ao efluente foi em um período de 6 horas. As análises de $\mathrm{pH}$ e condutividade foram feitas in situ do tempo 0 a 6 horas, o pHmetro utilizado foi o $827 \mathrm{pH}$ Lab da Metrohm e o condutivímetro utilizado é o 856 Conductivity Module da Metrohm. Para as demais análises foram coletadas alíquotas de hora em hora. Dentre os parâmetros analisados, tem-se o nitrogênio total pelo TNM-1 da Shimadzu, a concentração de íons nitrato por meio da utilização do medidor de nitrato 781 pH/ ion meter Metrohm e a concentração dos íons cromo por espectrometria de absorção atômica (Perkin Elmer Analyst 100). O sistema de eletrodiálise foi operado em modo estático e em fluxo (recirculação), em relação ao compartimento central da célula. Nos ensaios em fluxo foi utilizada bomba peristáltica (AWG 5000 ABS Provitec), com vazão de $100 \mathrm{~L} \mathrm{~h}^{-1},{ }^{25} \mathrm{com}$ fluxo ascendente.

Os resultados obtidos são expressos em termos de redução percentual de íons nitrato e cromo. Para íons nitrato foi utilizada a Equação 1.

$$
\mathrm{R}_{\text {redução }} \mathrm{NO}_{3}^{-}(\%)=\left[1-\mathrm{CN}-\mathrm{NO}_{3}{ }^{-} / \mathrm{C}_{0}\right] \times 100
$$

em que $\mathrm{C}_{0}$ é a concentração inicial de nitratos e $\mathrm{CN}-\mathrm{NO}_{3}{ }^{-}$é a concentração de nitrato no tempo t. Esta equação foi igualmente utilizada para a avaliação da redução percentual dos íons cromo presentes em solução. Além dos parâmetros mencionados, foi realizado o monitoramento dos íons ferro presentes no efluente por espectrometria de absorção atômica.

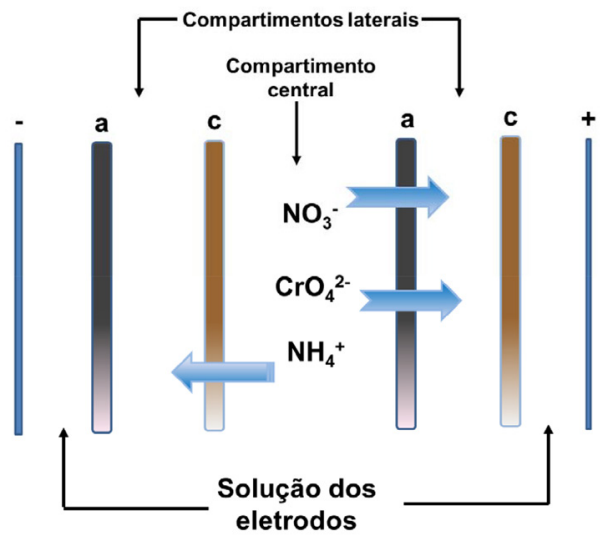

Figura 1. Esquema da célula e da passagem de íons no sistema estudado

\section{Ensaios de toxicidade do efluente antes e após a aplicação de eletrodiálise}

Utilizaram-se os organismos teste Artemia salina ${ }^{26}$ e Lactuca sativ $a^{27}$ para avaliação de toxicidade em dois diferentes níveis tróficos.

Para o teste de toxicidade com sementes de alface (Lactuca sativa) foram utilizadas alíquotas do efluente antes e após o tratamento, em concentrações do efluente de 10 e $100 \%$ com as quais foram realizados os ensaios. Para cada concentração, foi utilizada uma placa de petri com 10 sementes, sendo que sobre estas foi adicionado o efluente, onde foram cultivadas no período de 120 horas, com ausência de luz, com temperatura controlada de $25^{\circ} \mathrm{C}$. Após este período, as sementes foram retiradas da estufa de germinação (SL 225 Solab) para contagem e medição do desenvolvimento da raiz e caule.
Já para os testes de toxicidade com o organismo Artemia salina ${ }^{28}$ foram utilizadas alíquotas do efluente bruto e pós-tratamento. ${ }^{29}$ Foi utilizada solução aquosa contendo cloreto de sódio $27 \mathrm{~g} \mathrm{~L}^{-1}$ para a eclosão dos ovos da Artemia salina, com ajuste de $\mathrm{pH}$ para a neutralidade. Após eclosão e estabilização, foram transferidos 10 náuplios de Artemia salina para 24 tubos de ensaio utilizados como poços e adicionados $2 \mathrm{~mL}$ do efluente bruto e do efluente tratado por 6 horas, nas concentrações de 10, 20, 50, 80 e $100 \%$. As placas foram mantidas sob temperatura controlada entre 26 e $28{ }^{\circ} \mathrm{C}$ e proteção da luz. Foi verificado o número de sobreviventes no intervalo de 24 horas. ${ }^{30} \mathrm{O}$ ensaio foi realizado em triplicata de amostras.

\section{Reuso das soluções contendo íons recuperados por ED}

Após aplicação do tratamento de ED, a solução recuperada no compartimento anódico foi utilizada em estudos de tingimento de ágatas, avaliando a possibilidade de utilização desta após recuperação. Para a reutilização da solução, foi adicionado sal de amônio ao meio. Esta adição faz-se necessária em função do procedimento para tingimento de gemas com soluções que contém íons cromo ${ }^{2}$ seguindo as seguintes etapas: o tratamento envolve imersão inicial em solução aquosa contendo ácido crômico e sal de amônio, em pH ácido, na proporção 3:2 v/v. As gemas permanecem imersas nesta solução por 15 dias. Após lavagem, é realizado tratamento térmico em mufla, a $220^{\circ} \mathrm{C}$, por 48 horas. E como última etapa tem-se a lavagem final.

Após o processo de tingimento, a avaliação da coloração antes e após o processo de imersão seguido do tratamento térmico foi realizada segundo metodologia proposta, que se baseia na análise por scanner das gemas seguida de avaliação por software adequado em termos de parâmetros tais como brilho, cor, dentre outros, ${ }^{31,32}$ utilizando parâmetros do sistema cromático HSB (Hue, Saturation and Brightness).

\section{RESULTADOS E DISCUSSÃO}

\section{Aplicação da técnica de eletrodiálise}

A técnica de eletrodiálise foi aplicada por 6 horas em efluentes provenientes do processo de tingimento de ágatas. Os parâmetros condutividade, nitrogênio total (NT), concentração de nitratos e cromo foram avaliados em função do tempo de aplicação do experimento de eletrodiálise.

Na Figura 2 tem-se os resultados em termos de condutividade ( $\mathrm{mS}$ $\mathrm{cm}^{-1}$ ) para os efluentes do compartimento central (b) e dos compartimentos anódico e catódico (a) em função do tempo do tratamento de eletrodiálise, em célula estática.

Analisando os resultados apresentados na Figura 2, relativos ao experimento de ED estático, verifica-se que a condutividade relativa ao compartimento central (efluente antes do tratamento) tende a diminuir, sendo que inicialmente o efluente apresenta condutividade de $5,48 \mathrm{mS} \mathrm{cm}^{-1}$ e após 6 horas de tratamento a condutividade é igual a $1,5 \mathrm{mS} \mathrm{cm}^{-1}$. Já para os compartimentos laterais, catódico e anódico, respectivamente, no tempo inicial a condutividade é de $36,19 \mathrm{mS}$ $\mathrm{cm}^{-1}$, para ambos compartimentos, e após 6 horas a condutividade é de 43,01 e 40,13 mS cm$~^{-1}$, apresentando portanto valores crescentes em função do tempo de tratamento, demonstrando a passagem dos íons pelas membranas íon-seletivas, de forma crescente, durante o processo de ED. Para o sistema em fluxo, o comportamento foi semelhante em termos de variação de condutividade, ficando na mesma ordem de grandeza o decréscimo de condutividade no compartimento central. Já nos compartimentos laterais, a variação (incremento) de condutividade foi de $9,88 \mathrm{mS} \mathrm{cm}^{-1}$ no anódico e, no catódico, houve o incremento de $5,55 \mathrm{mS} \mathrm{cm}^{-1}$. 


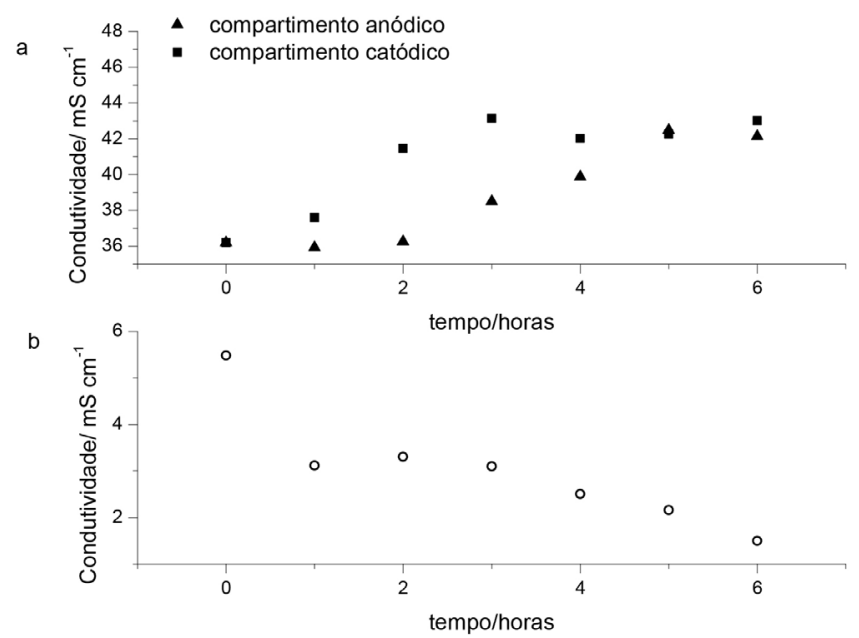

Figura 2. Valores de condutividade para os efluentes de tingimento de gemas durante o experimento de eletrodiálise estático, nos compartimentos anódico e catódico da célula de eletrodiálise (a) e central (b)

As concentrações de nitrogênio e cromo, em mg L $\mathrm{L}^{-1}$, também foram avaliadas nos diferentes compartimentos em função do tempo, na célula de eletrodiálise. Na Tabela 1 são apresentados os valores de NT, nitrato e cromo nos compartimentos central, anódico e catódico da célula de eletrodiálise para experimentos realizados em modo estático e em fluxo.

Tabela 1.Valores de nitrogênio total, nitrato e cromo (em $\left.\mathrm{mg} \mathrm{L}^{-1}\right)$ para os efluentes de tingimento de gemas antes e após tratamento de eletrodiálise estático e em fluxo

\begin{tabular}{|c|c|c|c|c|}
\hline \multirow[t]{2}{*}{$\begin{array}{l}\text { Tempo } \\
\text { (horas) }\end{array}$} & \multirow[t]{2}{*}{ Parâmetro } & \multicolumn{3}{|c|}{$\begin{array}{l}\text { Compartimen- Compartimen- Compartimen- } \\
\text { to catódico to Central to anódico }\end{array}$} \\
\hline & & \multicolumn{3}{|c|}{ Aplicação da ED em célula estática } \\
\hline 0 & $\mathrm{NT}\left(\mathrm{mg} \mathrm{L}^{-1}\right)$ & 0,0 & 373,8 & 0,0 \\
\hline 6 & & 23,0 & 0,0 & 10,7 \\
\hline 0 & Nitrato $\left(\mathrm{mg} \mathrm{L}^{-1}\right)$ & 5,7 & 500,0 & 5,7 \\
\hline 6 & & 0,1 & 10,2 & 31,5 \\
\hline 0 & Cromo $\left(\mathrm{mg} \mathrm{L}^{-1}\right)$ & 0,0 & 541,0 & 0,0 \\
\hline \multirow[t]{2}{*}{6} & & 0,0 & 55,0 & 197,0 \\
\hline & & \multicolumn{3}{|c|}{ Aplicação da ED em célula em fluxo } \\
\hline 0 & $\mathrm{NT}\left(\mathrm{mg} \mathrm{L}^{-1}\right)$ & 0,0 & 347,3 & 0,0 \\
\hline 6 & & 73,43 & 86,12 & 62,69 \\
\hline 0 & Nitrato $\left(\mathrm{mg} \mathrm{L}^{-1}\right)$ & 2,4 & 500,0 & 2,4 \\
\hline 6 & & 1,7 & 9,6 & 233,3 \\
\hline 0 & Cromo $\left(\mathrm{mg} \mathrm{L}^{-1}\right)$ & 0,0 & 541,0 & 0,0 \\
\hline 6 & & 12,7 & 37,0 & 223,6 \\
\hline
\end{tabular}

Por meio da avaliação dos resultados (Tabela 1), nos três compartimentos avaliados - central e laterais, após 6 horas de tratamento por eletrodiálise, espera-se que ocorra, no compartimento central, a diminuição da concentração de NT e nitratos, sendo que os resultados obtidos demonstram que houve redução de NT de $373,8 \mathrm{mg} \mathrm{L}^{-1}$ para $0 \mathrm{mg} \mathrm{L}{ }^{-1}$. Já em termos de nitrato, a concentração passou de $500 \mathrm{mg} \mathrm{L}^{-1}$ para 10,2 $\mathrm{mg} \mathrm{L}^{-1}$, para os experimentos no modo estático.

No compartimento anódico era esperado o aumento da concentração de nitrato, sendo que, com a aplicação do tratamento houve, neste compartimento, o aumento para $31,5 \mathrm{mg} \mathrm{L}^{-1}$ de nitrato e $10,7 \mathrm{mg} \mathrm{L}^{-1}$ em termos de concentração de nitrogênio.

Já no compartimento catódico a concentração de nitrogênio aumentou e passou para $23,0 \mathrm{mg} \mathrm{L}^{-1}$. Ou seja, ao final do tratamento, partindo de uma concentração inicial de nitrato de $373,8 \mathrm{mg} \mathrm{L}^{-1}$, obteve-se, em termos de recuperação e concentração nos compartimentos laterais, $54,5 \mathrm{mg} \mathrm{L}^{-1}$ em termos de concentração de espécies de nitrogênio. Estes resultados são concordantes com a representação apresentada na Figura 1, onde pode ser observada, de forma esquemática, a migração de íons pelas membranas ânion e cátion seletivas.

Comparando os resultados encontrados com estudos anteriores, ${ }^{33,34}$ verifica-se que o percentual de redução obtido para o íon nitrato está de acordo com o tempo de tratamento utilizado.

Em relação ao comportamento dos valores de $\mathrm{pH}$ nos compartimentos da célula durante a realização do tratamento de eletrodiálise, verifica-se que o compartimento central tende a manter o $\mathrm{pH}$ ácido. O compartimento catódico tende ao decréscimo do valor de $\mathrm{pH}$, em função da passagem dos prótons presentes inicialmente no compartimento central, sendo que em $\mathrm{t}_{0} \mathrm{o} \mathrm{pH}$ da solução de sulfato de sódio utilizada como solução dos compartimentos laterais é igual a 5. Já em relação ao compartimento anódico, há a tendência de incremento de $\mathrm{pH}$, em função especialmente das espécies de cromo que migram para este compartimento no decorrer do experimento, na forma de $\mathrm{CrO}_{4}{ }^{2-}$.

Em relação à remoção dos íons cromo presentes no efluente, houve uma expressiva redução percentual de $89,8 \%$ quando avaliado o compartimento central da célula. Comparando os resultados encontrados com estudos anteriores verifica-se, portanto, a eficiência do processo aplicado, sendo que o percentual de remoção de cromo é extremamente dependente das condições experimentais utilizadas quando da aplicação da técnica de ED..$^{35,36}$

Desta forma, a partir dos resultados obtidos para os experimentos de ED em modo estático verifica-se que houve a remoção em termos de íons nitrato e cromo, na avaliação relativa ao compartimento central, devendo ser considerado que houve a formação de precipitado neste compartimento durante o experimento de ED. Além da formação de precipitados, há também a decantação de materiais particulados ao fundo da célula no mesmo compartimento. A formação do precipitado insolúvel, que pode ser removido posteriormente por separação física, promove diferenças no somatório total, em termos de concentração de íons nitrato e cromo, quando comparados os valores iniciais e após 6 horas de tratamento, dos compartimentos central, anódico e catódico. A decantação de materiais particulados ao fundo da célula no compartimento central também pode ocasionar a variação do somatório de concentrações, devendo ser considerado que as soluções (efluente) antes do tratamento, quando da sua estocagem após coleta na indústria, igualmente apresentam pequena decantação de particulados. Isto pode ser explicado pela presença de concentrações de matéria orgânica (TOC $\approx 60 \mathrm{mg} \mathrm{L}^{-1}$ ) no efluente proveniente das etapas de corte e lapidação das gemas, com a utilização de óleo diesel marítimo como lubrificante, etapas estas que são realizadas previamente ao processo de tingimento. ${ }^{3}$

A ocorrência destes fenômenos durante a ED pode estar vinculada ao fato de que quando há o contato de soluções que contém ácido crômico com membranas aniônicas, estas podem ser gradualmente preenchidas com íons policromato (do tipo $\mathrm{Cr}_{n} \mathrm{O}_{3 n+1}^{2-}$ ), que são oxo-ânions com estrutura de tamanho maior resultante de ligações entre íons $\mathrm{HCrO}_{4}^{-}$tetraédricos. Este preenchimento diminui a mobilidade e aumenta a resistência da célula, podendo inclusive alterar a permeseletividade da membrana. ${ }^{37-39}$

Ainda, apesar da manutenção do pH ácido, há a tendência de aumento do $\mathrm{pH}$ no compartimento central (de $\mathrm{pH} 3$ para $\mathrm{pH}$ 4) pela migração de íons durante a ED, o que pode favorecer a precipitação e/ou complexação dos íons $\mathrm{Cr}^{3+}$ presentes no efluente..$^{39-41}$ 
Adicionalmente, há a presença de íons ferro no efluente em estudo, em concentrações iniciais de $124 \mathrm{mg} \mathrm{L}^{-1}$, que igualmente podem participar da formação de precipitados, considerando que apesar do $\mathrm{pH}$ ácido, a formação destes precipitados pode ser originada em função de variações locais do $\mathrm{pH}$, como por exemplo, na interface membrana/solução. ${ }^{42}$

A formação destes precipitados constitui-se em uma limitação $0^{43}$ da aplicação do tratamento de eletrodiálise, que pode ser minimizada com alterações de layout da célula e condições de realização dos experimentos, ${ }^{44,45}$ sendo que a agitação do sistema pode minimizar esses efeitos..$^{25,46}$

Já em relação aos experimentos em fluxo, houve a recuperação de $306,73 \mathrm{mg} \mathrm{L}^{-1}$ de íons nitrogenados, e $223,6 \mathrm{mg} \mathrm{L}^{-1}$ de íons cromo hexavalente. Verifica-se que para esta condição experimental o fenômeno de precipitação é minimizado, bem como a decantação. Estes resultados superiores em termos de eficiência de remoção podem estar relacionados com o incremento de íons transportados devido à turbulência local na interface solução/membrana. ${ }^{25}$

\section{Ensaios de toxicidade do efluente antes e após a aplicação de eletrodiálise}

Em termos de toxicidade foram avaliados dois organismos teste, sendo que inicialmente avaliou-se a toxicidade frente à Artemia sali$n a$, e posteriormente a fitotoxidade foi avaliada utilizando-se sementes de Lactuca sativa. A avaliação em diferentes níveis tróficos segue orientações de resoluções ambientais vigentes. ${ }^{47}$

Na Tabela 2 são mostrados os resultados obtidos a partir dos ensaios de toxicidade aguda utilizando como organismo teste a Artemia salina. Os resultados foram comparados em termos de percentual de mortalidade ${ }^{48}$ da Artemia salina para o efluente bruto e tratado (após $6 \mathrm{~h}$ de ED).

Avaliando a Tabela 2, pode-se verificar que o efluente bruto, nas diferentes concentrações avaliadas, apresentou toxicidade aguda em níveis elevados frente à Artemia salina. Já o efluente após ser submetido ao tratamento de eletrodiálise (em sistema estático) teve sua toxicidade diminuída, sendo que a Concentração Letal $\left(\mathrm{LC}_{50}\right)$ para o efluente tratado é de $\mathrm{LC}_{50}=17 \%$. Já para o modo em fluxo, os resultados foram ainda mais interessantes em termos de redução de toxicidade após ED, sendo que para todas as concentrações analisadas a letalidade ficou abaixo de $50 \%$. Resultados obtidos em efluentes ${ }^{49}$ contendo cromo indicaram elevado $\mathrm{LC}_{50}$ com efeitos prejudiciais em diferentes organismos, resultados estes que confirmam os obtidos no presente estudo, já que os efluentes tratados por ED em fluxo foram menos tóxicos, provavelmente em função dos valores de concentração menores em termos de íons cromo após aplicação do tratamento.

Em termos de avaliação de fitotoxidade, os efluentes bruto e tratado (ED modo estático) apresentaram alta toxicidade em função da completa letalidade promovida nas sementes de Lactuca sativa. Já quando estes são diluídos a $10 \%$, verifica-se que há uma tendência de diminuição do percentual de letalidade após a aplicação da técnica de
ED em modo estático. Porém, cabe salientar que mesmo apresentando redução de toxicidade, o efluente após tratamento ainda apresenta fitotoxidade elevada, demonstrando a importância de avaliação da toxicidade em mais de um nível trófico. O efluente bruto apresentou percentual de letalidade de $91,85 \%$, já o efluente tratado $85,74 \%$. Em relação ao efluente na concentração $10 \%$, tratado por ED em fluxo, o percentual de letalidade foi de $83 \%$.

Estudos demonstraram que há um significativo aumento da mortalidade das sementes de Lactuca sativa na presença de cromo. ${ }^{50}$ Além disso, o alongamento da raiz foi a medida mais sensível em termos de inibição.

\section{Reuso das soluções contendo íons recuperados por ED}

Em termos de avaliação de possibilidade de reuso, em relação aos íons recuperados após aplicação da técnica de ED em fluxo, em especial o íon cromo, estes podem retornar para o banho de tingimento utilizado no beneficiamento de gemas, ${ }^{1}$ e a água tratada do compartimento central pode ser incorporada ao banho de lavagem, consistindo na segunda etapa do processo de tingimento de gemas, ou ainda adicionada ao tanque de lavagem após tratamento térmico das gemas coradas.

Em estudos realizados pelo grupo de pesquisa, verificou-se a possibilidade de tingimento de ágatas com solução proveniente do compartimento anódico após aplicação da técnica de ED.

Na Figura 3 podem ser avaliadas imagens, do aspecto visual, de gemas antes e após tingimento utilizando soluções contendo majoritariamente íons cromo recuperados pela técnica de ED. A avaliação por meio da utilização de scanner permitiu verificar que as gemas após terem sido submetidas ao processo de tingimento em soluções recuperadas pela técnica de ED apresentaram tons entre amarelo e verde,${ }^{31}$ enquanto que as não tingidas apresentaram, pela avaliação, tons cinza azulado, característicos de ágata no estado bruto, ${ }^{2}$ indicando a viabilidade de aplicação deste processo.

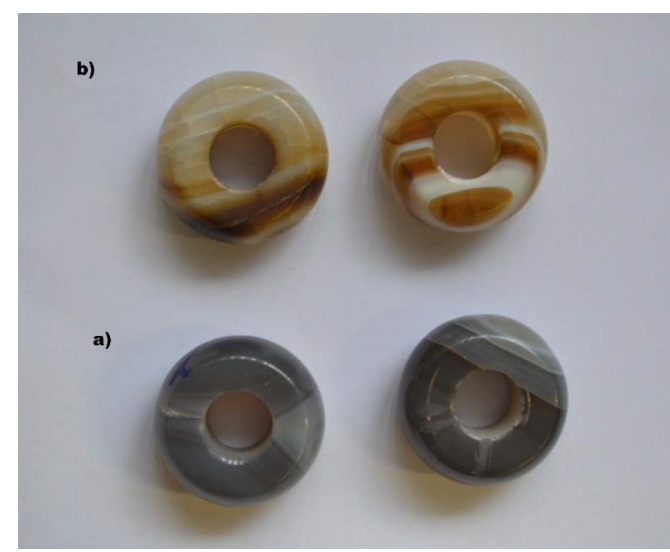

Figura 3. Imagens das gemas antes (a) e após tingimento (b) com solução recuperada pela técnica de eletrodiálise

Tabela 2. Toxicidade aguda com Artemia salina (microcrustáceo), após 24 h de incubação em diferentes concentrações de efluente, antes e após ED estática e em fluxo

\begin{tabular}{cccc}
\hline Concentração do Efluente (\%) & $\begin{array}{c}\text { Percentual de letalidade no Efluente } \\
\text { Bruto }(\%)\end{array}$ & $\begin{array}{c}\text { Percentual de letalidade no Efluente } \\
\text { Tratado após ED estática (\%) }\end{array}$ & $\begin{array}{c}\text { Percentual de letalidade no Efluente } \\
\text { Tratado após ED em fluxo (\%) }\end{array}$ \\
\hline 100 & $100 \pm 0,0$ & $100 \pm 0,0$ & $43 \pm 4,1$ \\
80 & $100 \pm 0,0$ & $85 \pm 5,0$ & $36 \pm 2,8$ \\
50 & $100 \pm 0,0$ & $90,0 \pm 0,0$ & $0 \pm 0,0$ \\
20 & $93,3 \pm 4,7$ & $85,0 \pm 15,0$ & $0 \pm 0,0$ \\
10 & $96,6 \pm 4,7$ & $40,0 \pm 16,3$ & $0 \pm 0,0$ \\
\hline
\end{tabular}


Cabe ressaltar que, por este setor produtivo se configurar como um setor vinculado à economia criativa, este segue tendências de mercado vinculadas ao processo de criação, sendo que as colorações e tonalidades podem sofrer alterações de uma coleção para outra, exigindo a possibilidade de minimização de impactos ambientais, sendo adequada a possibilidade de produção em ciclo fechado.

Ainda é importante destacar que a incorporação de práticas que permitam o reuso de água e insumos se torna cada vez mais necessária. Diversos estudos têm sido publicados apresentando resultados de aplicação de técnicas avançadas de tratamento de efluentes, mas poucos discutem e apresentam alternativas de reuso, ${ }^{51}$ sendo esta uma medida altamente desejável, buscando diminuir o consumo de água e insumos e reduzir os custos de produção.

\section{CONCLUSÕES}

Os resultados obtidos nesse estudo evidenciaram que é válida a possibilidade de utilizar a técnica de eletrodiálise como um tratamento de efluentes contendo íons metálicos nas indústrias de gemas, principalmente no tingimento de ágatas. Verificou-se uma redução na condutividade das soluções do compartimento central e incrementos nos compartimentos laterais após 6 horas de tratamento em modo estático e em fluxo, o que expressa a passagem de íons pelas membranas íon-seletivas. Houve a recuperação de $306,73 \mathrm{mg} \mathrm{L}^{-1}$ de íons nitrogenados e 223,6 $\mathrm{mg} \mathrm{L}^{-1}$ de cromo hexavalente inicialmente presentes no efluente bruto, o que demonstra a eficiência da técnica de ED em fluxo. Ensaios de toxicidade com Artemia salina e Lactuca sativa apresentaram uma redução na porcentagem de mortalidade de organismos após o tratamento da ED. Os resultados apontam a possibilidade do reuso de íons, principalmente cromo, em um subsequente processo de tingimento de ágatas.

\section{MATERIAL SUPLEMENTAR}

No material suplementar, disponível em http://quimicanova.sbq. org.br na forma de arquivo PDF, com acesso livre, está a curva de polarização relativa aos ensaios para determinação da corrente limite para o sistema em estudo (Figura 1S).

\section{AGRADECIMENTOS}

Os autores agradecem a Capes e CNPq (processo n 310421/20136) pelos auxílios concedidos.

\section{REFERÊNCIAS}

1. Brum, I. A. S.; Silva, R. A. Em Tecnologia para o Setor de Gemas, Joias e Mineração; Hartmann, L. A.; da Silva, J. T., eds.; UFRGS: Porto Alegre, 2010, cap. 15 .

2. Silva, R. de A.; Petter, C. O.; Schneider, I. A. H.; REM, Rev. Esc. Minas 2007, 60, 477.

3. Pshenichnyi, M. I.; Russ. J. Gen. Chem. 2011, 81, 1375.

4. Machado, E. L.; Dambros, V. S.; Kist, L. T.; Lobo, E. A. A.; Tedesco, S. B.; Moro, C. C.; Water, Air, Soil Pollut. 2012, 223, 1753.

5. Jain, R.; Mathur, M.; Sikarwar, S.; Mittal, A.; J. Environ. Manage. 2007, $85,956$.

6. Sahoo, C.; Gupta, A. K.; Pal, A.; Dyes Pigm. 2005, 66, 189.

7. Saha, P. D.; Chakraborty, S.; Chowdhury, S.; Colloids Surf., B. 2012, 92, 262.

8. Pizzolato, T. M.; Carissimi, E.; Machado, E. L.; Schneider, I. A. H.; Int. J. Miner. Process. 2002, 65, 203.

9. Barros, A. L.; Pizzolato, T. M.; Carissimi, E.; Schneider, I. A. H.; Miner. Eng. 2006, 19, 87.
10. Valerdi-Pérez, R.; Ibáñez-Mengual, J. A.; Desalination 2001, 141, 23.

11. Marder, L.; Bernardes, A. M.; Ferreira, J. Z.; Sep. Purif. Technol. 2004, 37, 247.

12. Chen, S-S.; Li, C-W.; Hsu, H-D.; Lee, P-C.; Chang, Y-M.; Yang, C-H.; J. Hazard. Mater. 2009, 161, 1075.

13. Nataraj, S. K.; Hosamani, K. M.; Aminabhavi, T. M.; Desalination 2007, $217,181$.

14. Menkouchi Sahli, M. A.; Annouar, S.; Mountadar, M.; Soufiane, A.; Elmidaoui, A.; Desalination 2008, 227, 327.

15. Ndusekhar, V. K.; Trivedi, G. S.; SHAH, B. G.; Desalination 1991, 84, 213.

16. Menkouchi Sahli, M. A.; Tahaikt, M.; Achary, I.; Taky, M.; Elhanouni, F.; Hafsi, M.; Elmghari, M. Elmidaoui, A.; Desalination 2004, 167, 359

17. Bosko, M. L.; Rodrigues, M. A. S.; Ferreira, J. Z.; Miró, E. E.; Bernardes, A. M.; J. Membr. Sci. 2014, 451, 276.

18. Brett, C. M. A.; Brett, A. M. O.; Electrochemistry: principles, methods and applications, $1^{\text {st }}$ ed., Oxford Science: London, 2005.

19. Strathmann, H.; Íon-exchange membrane separation processes. Membrane Science and Technology Series, $1^{\text {st }}$ ed., Elsevier: Amsterdam, 2004.

20. Tahaikt, M.; Achary, I.; Menkouchi Sahli, M. A.; Amor, Z.; Taky, M.; Alami, A.; Boughriba, A.; Hafsi, M.; Elmidaoui, A.; Desalination 2004, $167,357$.

21. Marder, L.; Sulzbach, G. O.; Bernardes, A. M.; Ferreira, J. Z.; J. Braz. Chem. Soc. 2003, 14, 610.

22. Banasiak, L. J.; Kruttschnitt, T. W.; Schäfer, A. I.; Desalination 2007, $205,38$.

23. Grigorchuk, O. V.; Vasil'eva, V. I.; Shaposhnik, V. A., Kuz'minykh, V. A.; Russ. J. Electrochem. 2003, 39, 777.

24. Vera, E.; Sandeaux, J.; Persin, F.; Pourcelly, G.; Dornier, M.; Ruales, J.; J. Food Eng. 2007, 78, 1427.

25. Cifuentes, L.; García, I.; Arriagada, P.; Casas, J. M.; Sep. Purif. Technol. 2009, 68, 105.

26. Pimentel, M. F.; Silva Júnior, F. C. G.; Santaella, S. T.; Lotufo, L. V. C.; J. Braz. Soc. Ecotoxicol. 2011, 6, 15 .

27. Garcia, J. C.; Simionato, J. I.; Almeida, V. C.; Palácio, S. M.; Rossi, F. L.; Schneider, M. V.; de Souza, N. E.; J. Braz. Chem. Soc. 2009, 20, 1589.

28. Coelho, G. A.; Weinschutz, R.; Dallavalli, M. J.; Mathia, A. L.; Rev. Arvore 2014, 38, 927.

29. Meyer, B. N.; Ferrigni, N. R.; Putnam, L. B.; Jacobsen, L. B.; Nichols, D. E.; Mclaughlin, J. L.; J. Med. Plants Res. 1982, 45, 31.

30. Migliore, L.; Civitareale, C.; Brambilla, G.; Di Delupis, G. D.; Water Res. 1997, 31, 1801.

31. Motoki, A.; Zucco, L. L.; Sichel, S. E.; Aires, J. R.; Petrakis, G. H.; Geociências 2006, 5, 403.

32. Motoki, A.; Vargas, T.; Peixoto, J. L. N.; Min. Metal. 2000, 554, 14.

33. Menkouchi Sahlia, M. A.; Tahaikta, M.; Acharya, I.; Takya, M.; Elhanounia, F.; Hafsib, M.; Elmgharib, M.; Elmidaouia, A.; Desalination 2006, 189, 200.

34. Schoeman, J. J.; Water SA 2009, 35, 721.

35. Hsu, H.-T.; Chen, S.-S.; Chen, Y-S.; Sep. Purif. Technol. 2011, 80, 663.

36. Moura, R. C. A.; Bertuol, D. A.; Ferreira, C. A.; Amado, F. D. R.; Int. J. Chem. Eng. 2012, 2012, ID 179312.

37. Vallejo, M. E.; Persin, F.; Innocent, C.; Sistat, P.; Pourcelly, G.; Sep. Purif. Technol. 2000, 21, 61 .

38. De Körösy, F.; Zeigerson, E.; Desalination 1968, 5, 185.

39. Jin, W.; Du, H.; Zheng, S.; Zhang, Y.; Electrochim. Acta 2016, 191, 1044.

40. Mandich, N. V.; Plat. Surf. Finish. 1997, 84, 108.

41. Medina, B. Y.; Torem, M. L.; Mesquita, L. M. S.; Miner. Eng. 2005, 18 , 225.

42. Chekioua, A.; Delimi, R.; Energy Procedia 2015, 74, 1418. 
43. Bannoud, A.; Desalination 1993, 93, 545.

44. Feng, X. Wu, Z. Chen, X. Sep. Purif. Technol. 2007, 57, 257.

45. Dermentzis, K.; J. Hazard. Mater. 2010, 173, 647.

46. Brauns, E.; Bossaer, J.; Toye, S.; Mijnendonckx, K.; Pinoy, L.; Van der Bruggen, B.; Sep. Purif. Technol. 2012, 98, 356.

47. BRASIL. Ministério do Desenvolvimento Urbano e Meio Ambiente. Conselho Nacional do Meio Ambiente (CONAMA); Resolução do no 430, de 13/05/11, Brasília: Brasil.
48. de Souza, S. M. A. G. U.; Forgiarini, E.; de Souza, A. A. U.; J. Hazard. Mater. 2007, 147, 1073.

49. Arias-Barreiro, C. R.; Nishizaki, H.; Okubo, K.; Aoyama, I.; Mori, I. C.; J. Environ. Biol. 2010, 31, 471-475.

50. Naaz, S.; Pandey, S. N.; J. Environ. Biol. 2010, 31, 273.

51. Zanella, G.; Scharf, M.; Vieira, G. A.; Peralta-Zamora, P.; Quim. Nova 2010, 33, 1039. 